\title{
Key themes in mobile learning: Prospects for learner-generated learning through AR and VR
}

\author{
Claudio Aguayo, Thomas Cochrane, Vickel Narayan \\ Auckland University of Technology
}

\begin{abstract}
This paper summarises the findings from a literature review in mobile learning, developed as part of a 2-year six-institution project in New Zealand. Through the development of a key themes codebook, we address selected key themes with respect to their relevance to learner-generated learning through emerging technologies, with attention to mobile augmented reality and mobile virtual reality. We see that these two current mobile learning affordances, complemented though relevant approaches to research and practice in mobile learning such as design-based research and connected social learning, are critical to reconceptualise learning through mobile devices. We conclude that mobile learning still requires the theories, methodologies, and practices of its own as a field. We also see a need for mobile learning to be conceptualised around ever-changing learning affordances and educational settings, rather than focusing on static structures such as content-delivery approaches, while embedding it within the scholarship of technology enhanced learning.
\end{abstract}

\section{Introduction}

Cook and Santos (2016) argue for the emergence of three aspects of mobile learning: the integration with social media for connecting learners and work-based practice, the use of design research to guide mobile learning implementation, and learner-generated content and contexts in learning. Mobile learning (re)conceptualised around what learners can do and create through mobile affordances (the range of possibilities offered by mobile technology), that is learner-generated content and context or heutagogy (Hase \& Kenyon, 2007; 2013), enables going beyond device centric and content-focused pedagogical delivery approaches. Mobile learning facilitates new patterns of connected social learning around the transformative possibilities of digital tools (Cook \& Santos, 2016). It allows for learning processes to occur practically anywhere in collaboration with anyone, and promote innovative (Kukulska-Hulme, Sharples, Milrad, Arnedillo-Sanchez, \& Vavoula; Parsons, 2012), inclusive (Attewell, Savill-Smith, \& Douch, 2009; Traxler, 2010) and transformative (Lindsay, 2015; Pachler, Bachmair, \& Cook, 2010) types of learning that challenge traditional pedagogical approaches (Cochrane, 2014; Merchant, 2012). The potential of mobile learning resides in enabling authentic learning experiences across augmented contexts through learner-generated learning, facilitated by the increasingly sophisticated and unique affordances of emerging digital tools.

What learners can do and create through mobile technology depends on the affordances technology can offer, and in turn on the understanding of such affordances by learners (Dohn, 2009; McGrenere \& Ho, 2000). Both factors, the technological affordances and the understanding of them by users, are in turn influenced by the socio-cultural characteristics of learning environments (Aguayo, 2016; Knight, Gunawardena, \& Aydin, 2009; Pachler et al., 2010). Since the early days of mobile learning and mobile devices, we have seen a rapidly evolving field where practice has had to adapt by using existing learning theories and frameworks at hand, as a response to a lack of field specifics theories and frameworks (Naismith, Lonsdale, Vavoula \& Sharples, 2004; Pachler et al., 2010; Sharples, Taylor \& Vavoula, 2007).

As part of a 2-year six-institution national project throughout 2014-2015 about tertiary learners and mobile devices in New Zealand (\#npf14lmd: Learners and Mobile Devices project) (Frielick \& Sciascia, 2016), we conducted a literature review targeting the origins, developments, and current state of the art in mobile learning across disciplines and educational sectors. The intention was to qualitatively capture the broad range and scope of key themes present in the literature relating to different aspects of mobile learning, including theoretical, methodological and practical aspects, among others. Here we present a set of those key themes, and situate them in the context of their relevance to learner-generated learning through mobile augmented reality (AR) and mobile virtual reality (VR). By doing so our intention is to, first, provide an overview of the key themes and gaps in mobile learning; and second, situate the unique potential of emerging mobile learning affordances, such as AR and VR, in the reconceptualisation of 
learning through mobile devices. In this process, we seek to conceptually explore the knowledge boundaries of how new patterns of collaborative networked pedagogies, through authentic learning and professional practice, can enable learning experiences through learner-generated learning.

\section{Literature review}

The strategy for the literature review of the \#npf14lmd project was to first review previous mobile learning literature reviews and reports. An initial thematic analysis of six key publications from 2004 to 2012 led to the identification of recurrent themes within mobile learning This allowed for a metaoverview of a broad range of topics, issues, concepts, and gaps relevant to mobile learning. This initial process permitted the development of a 3-tier codebook representing the main themes within the field, which were grouped under five broad areas of interest to the project: (1) philosophical and theoretical frameworks; (2) mobile learning research; (3) pedagogies and learning methodologies; (4) mobile learning affordances; and (5) key issues in mobile learning. Further thematic literature review targeting more recent literature from prominent journals and other related sources complemented the initial codebook. Qualitative data analysis using NVivo enabled the interpretation and allocation of clusters of data, themes, and findings into different domains and areas of mobile learning. Findings were finally incorporated into the codebook, which represented a broad range of key themes within mobile learning literature.

The initial thematic scoping of the literature was based on the following six previous literature reviews and reports on mobile learning:

- $\quad$ Literature review in mobile technologies and learning (Naismith et al., 2004)

- Big issues in mobile learning: Report of a workshop by the Kaleidoscope network of excellence mobile learning initiative (Sharples, 2006)

- Mobile learning projects: A critical analysis of the state of the art (Frohberg, Göth \& Schwabe, 2009)

- Mobile learning: Structures, agency, practices (Pachler et al., 2010)

- A survey of research methods and purposes in mobile learning (Wingkvist \& Ericsson, 2011)

- Review of trends from mobile learning studies: A meta-analysis (Wu et al., 2012)

These documents were arbitrarily chosen as we considered them to offer a representative sample of a wide range of themes and topics relevant to mobile learning, and to the scope of the \#npf14lmd project (see http://mobilelearners.nz/ for details), covering the previous 10 years of literature from the start of the project. In the first, Naismith et al. (2004) explicitly intended to address what they considered a gap in the emerging use of mobile technologies at the time: the lack of learning theories informing emerging practice using mobile technologies. They highlight how "previous reviews of mobile technologies for learning categorise examples of use according to curriculum area" (p. 7), and that "much of the research into the use of mobile technologies for learning is driven by the technical capabilities of new devices” (p. 9). In an effort to map existing learning theories to the educational possibilities of mobile devices, the authors propose a classification of types of activities around the main theories and learning areas relevant to learning through mobile technologies. They do so based on what they regarded as key educational affordances of mobile devices (PDAs at the time): portability, social interactivity, context sensitivity, connectivity, and individuality (Klopfer, Squire, \& Jenkins, 2002). Through this process Naismith et al. (2004) identify six types of activities: behaviourist learning, constructivist learning, situated learning, collaborative learning, informal and lifelong learning, and learning and teaching support. The authors further highlight the importance of the learning context stressing the need to go beyond the individual and naked use of mobile devices. Finally, and based on findings from the MOBIlearn project (O'Malley et al., 2003), the authors propose a set of guidelines for the effective implementation of mobile devices in educational contexts (see Naismith et al. 2004 for details).

The Big issues in mobile learning report (Sharples, 2006) summarised the discussions and findings of a 2day workshop organised by the Kaleidoscope European Network of Excellence in technology enhanced learning, where key European researchers in mobile learning reflected on the issues behind the blossoming growth of the field in Europe. As reported by Sharples, one issue that became clear during the workshop is that mobile learning was seen as not just about learning using mobile technologies, but learning across learning contexts with context seen as an emergent phenomenon (Dourish, 2004). Key 
questions such as how to measure learning in mobile environments, or how to address the conflicts emerging between traditional classroom education and informal learning led to fruitful insights into the pedagogical landscape of mobile learning. Other critical topics discussed included the need to focus on activities and the interaction occurring between learners and technology (rather than in isolation), the collaborative social learning capacity of mobile learning and design principles needed to achieve this capacity, and the gaps needed to be filled to advance the research agenda within mobile learning.

In a more recent review Frohberg et al. (2009) examined more than a hundred mobile learning projects synthesising central benefits and values for each type of mobile learning reported, with the intention of discovering "common ground and similarities, along with differences, inconsistencies or contradictions within the domain of mobile learning” (p. 308). They followed Sharples and Taylor's task model for mobile learners designed to analyse mobile learning both in a detailed and at the meta-level (Sharples et al., 2007; Taylor, Sharples, Malley, Vavoula, \& Waycott, 2006). The task model is an expansion of Engeström's activity theory (Engeström, 1987) enhancing it by focusing on the interdependencies and dialectic of learning and technology. One interesting pattern that emerged was that most projects were geared for novice or low knowledge learners. As indicated by Frohberg et al. (2009), although this might seem natural and almost irrelevant, the trade-off is therefore the lack of support for learners that have acquired a certain level of knowledge and expertise and are willing to advance further. As stated by the authors, “in accordance with Bloom's well-known taxonomy of educational objectives (Bloom, 1953), mobile learning should no longer limit itself to create knowledge and comprehension, but rather support learners in applying, analysing, synthesizing and evaluating their knowledge” (p. 322), suggesting a need to support advanced learners. Concluding remarks from Frohberg et al. (2009) not only highlight how the potential of mobile learning is still hidden, in particular regarding learning in context, but also stress the need to focus on designing mobile learning environments that invite learners to deep-reflection, communication, cooperation, and collaboration.

Within the same trend of addressing the need for comprehensive frameworks and unifying understandings in mobile learning, Pachler et al.'s (2010) book Mobile learning: Structures, agency, practices provides an in-depth conceptual and practical mapping of the field. The authors review a range of key issues relevant to mobile learning, with a focus on the socio-cultural conditions and cultural resources for learning through technology, rather than on technological innovation itself. They refer to this as the sociocultural ecological approach, emphasising that mobile learning needs to be situated and understood in the context of the fundamental and complex societal and cultural transformations in place in our modern society. In this regard, Kress and Pachler (2007) point that mobile learning is about individuals going "beyond the acquisition of knowledge relevant to issues encountered in the world but also to shape their knowledge out of their own sense of the world” (p. 22). Two key central aspects addressed by Pachler et al. (2010) as critical for understanding the significance and potential of mobile learning and its successful adoption are: (1) learner-generated contexts, with the notion of learner-generated seen as a paradigm shift from learning as content to learning as context in a meaning-making process triggered by social interactions and communication, facilitated by technological structures; and (2) appropriation. Appropriation here is seen as the adoption of mobile devices through meaning-making processes that are relevant to learners' emerging contexts: in other words, authentic learning. Pachler et al. (2010) address many other key issues in mobile learning, for example mobility of learners, mixed reality learning spaces, public and intimate spaces, development of mobile learning professionals, and visions for the field, among many others. Although these issues are relevant to us, they fall outside the scope and breadth of this review article.

In another review of mobile learning trends, Wingkvist and Ericsson (2011) acknowledge the rapid growth in research, development and implementation of mobile learning across educational contexts (Kukulska-Hulme et al., 2009), yet recognise that "research conducted into mobile learning is often small-scale and has seldom been developed into learning aids that are in wide use" (Wingkvist \& Ericsson, 2011, p. 1). With the intention of developing an understanding of research methods and purposes in mobile learning, the authors conducted a survey of published research in mobile learning investigating 114 papers from the mLearn conference proceedings from 2005, 2007, and 2008. Recognising that research methods often overlap, they identified eight types of research methods based on the defining characteristics of each one of them for the purpose of their classification of research in mobile learning: case studies, field studies, action research, experiment studies, survey research, applied research, basic research, and normative research. In addition, and following Benbasat's (1985) criteria, 
they grouped these eight research methods under either environment dependent, artificial, or environment independent. Case studies, field studies, and action research were seen as methods used in natural, or reallife settings, experiment studies as being carried out in somewhat artificial studies, and the remaining four (survey, applied, basic and normative research) as being somehow all environment independent, yet not artificial studies. Wingkvist and Ericsson (2011) provide a useful summary table of the above classification, indicating the strengths, weaknesses, and types of use of each research method (see original article for further reference).

In terms of research purposes, and acknowledging that "the purpose of a research effort is closely linked to the research method used and vice versa” (p. 6), Wingkvist and Ericsson (2011) propose four types of research purposes: describing (writings that describe the unit under study); developing (writings that define theoretical and/or technical frameworks); understanding (writings that seek to understand and make sense of conducted research); and evaluating (writings that evaluate the usefulness, benefits, and shortcomings of research). Findings from Wingkvist and Ericsson (2011) show that the most common research method is the normative research (25\%), followed by case studies (22\%) and applied research (17\%), with the least commons being action research (4\%) and basic research (2\%). Environment independent $(55 \%)$ was the most common type of environment reported, followed by environment dependent (36\%) and artificial (9\%). Regarding research purposes, describing studies was the most common purpose (57\%), followed by developing (25\%), understanding (15\%), and evaluating (3\%) (for further insights refer to Wingkvist and Ericsson's review). Gaps identified by the authors are a lack of richness between the two most, yet opposite in essence, employed research methods, that is case studies (empirical data collection) and normative research (utilisation of mobile learning in abstract ways), both representing almost half of the sample. Another gap in the reviewed literature is the lack of evaluation and basic research, as "much of the research is done to describe, not understand or evaluate. This may indicate a lack of maturity and lack of clear definitions" (p. 10). Wingkvist and Ericsson (2011) further state that the speed with which mobile technologies develop could be another reason for the low level of evaluation and basic research studies.

In another review of the literature, Wu et al. (2012) expand on Hwang and Tsai's (2011) and Hung and Zhang's (2012) literatures reviews on mobile learning issues and research domain trends, and formulate "a more comprehensive examination and analysis of mobile devices, learners, disciplines and courses" (Wu et al., 2012, p. 818). They do so by focusing on the major research purposes, methodologies, and outcomes in mobile learning. Following a systematic review and analysis from a data pool of bibliographic databases (e.g., Wiley InterScience, ERIC, and SAGE), the authors identified 164 studies published from 2003 to 2010 and complying with their criteria, which included being primarily focused on mobile learning, having an identifiable learner level, and involving education activities when implementing mobile learning, among others (see reference for further details). They then performed data coding and analysis based on 10 features related to the quality of research methodologies, as deemed relevant by the authors, including categories of research purpose, learner demographics, method employed, discipline-orientation, and learning context. In contrast to Wingkvist and Ericsson's (2011) findings, and acknowledging the different backgrounds and approaches employed by these two reviews, Wu et al. (2012) report that the most common research purpose in mobile learning are evaluating studies (58\%), followed by designing mobile system for learning (32\%), investigating the affective domain in mobile learning (5\%), and evaluating the influence of learners' characteristics in the learning process (5\%).

In the context of this review article, the above accounts presented from the six previous literature reviews and key reports in mobile learning tell us, among other things, that the field has been in a constantly rapid transition and evolution since the early days of mobile learning, with its potential still latent. We can also see some references to the three key aspects of mobile learning reported by Cook and Santos (2016) addressed at the beginning of this article. For example, both Naismith et al. (2004) and Sharples (2006) refer to the need to address ideas relating to connected and collaborative social learning through mobile devices, with Sharples particularly calling for design principles required to achieve so. Or the need for mobile learning to focus on affordances that enhance authentic learning across emerging environments and contexts within learner-generated learning modes of learning (Naismith et al., 2004; Pachler et al., 2010; Sharples, 2006). In addition, the above overview of the literature also sheds light on the commonly found range of issues in mobile learning, for example a lack of theoretical frameworks and common 
understandings, and therefore of maturity as a field, as well as the different and growing approaches existing in the field represented by the diversity of key topics that emerged from the literature.

In terms of approaches for future directions, Wingkvist and Ericsson (2011) state that stopping and reflecting on past results once again as a challenge for the field could help in reaching a "visionary future” (p. 11) and in reconceptualising mobile learning. On the other hand, Parsons (2014), who also recounts the key themes in mobile learning research over the past 20 years, concludes that:

[T] he message from the timeline for current researchers is to cast their eye beyond current technology and practice and imagine the potential opportunities for the mobile learning that are not yet even possible or practical" (pp. 13-14).

More recently, Traxler (2016) in addressing the failure of mobile learning states:

Mobile learning has stalled. It has spent quite some time barking up the wrong tree, looking backwards and inwards. I'd like to direct the community's attention onward and outward instead. (para. 19)

Within such spirit of reflecting on previous successes and failures, and looking ahead with the unpredictable and yet-to-emerge in mind, through our initial qualitative analysis of key themes in mobile learning taken from reviewing previous reviews we identified more than 15 Level 1 key themes in mobile learning, which we translated into a codebook for further coding of more recent literature. The aim of this process is to situate the emerging focus on learner-generated learning through newer mobile learning technologies and affordances, such as mobile AR and mobile VR, in the historical context of the field, and within the range of key themes currently existing in mobile learning, as addressed by this special issue of AJET. We expand on this in the next section.

\section{Key themes in mobile learning: A qualitative meta-analysis}

Following the development of the initial codebook addressing key themes in mobile learning from the first iteration of literature review, as described above, we continued the qualitative meta-analysis through recurrent theme analysis of the literature by reviewing 328 publications from selected prominent journals (e.g., AJET, BJET, Computers \& Education, EURODL, IJMBL), conference proceedings (e.g., ASCILITE, MLearn, Molta), books, and other sources addressing mobile learning from 2010 to 2016. These publications were selected through data mining and search engines using different keywords, including: m-learning, mobile, device, phone, social media, tablet, emerging technology, ubiquity, handheld, smart device, and digital technology.

Using the initial codebook as reference, this second review process involved the identification of thematic patterns through descriptive and inferential coding and analysis of these publications following La Pelle's "clever but simple" qualitative data analysis method (2004, p. 85). This method uses Microsoft Word tables and associated data management tools for the organisation, management, coding, interpretation, and presentation of data. The use of table structures can be a powerful analytical tool usable in manageable ways as a database for analysis (Miles \& Huberman, 1994). Further qualitative data analysis using NVivo followed. This process enabled the interpretation and allocation of clusters of data, themes and findings into different thematic sections of the codebook. Through this process, we improved and complement the richness of the original codebook.

Note that this is an evolving codebook that we are enhancing and complementing on an ongoing basis as new literature is being reviewed and processed, and thus new themes are being added to the codebook. To March 2017, we have identified 21 Level 1 themes, 93 Level 2 themes, and 214 Level 3 themes. Table 1 presents selected Level 1, Level 2, and Level 3 themes related to learner-generated learning through emerging technologies, organised within the five broad areas of mobile learning presented earlier: (1) philosophical and theoretical frameworks; (2) mobile learning research; (3) pedagogies and learning methodologies; (4) mobile learning affordances; and (5) key issues in mobile learning. Accounts on all key themes identified through this process will be reported elsewhere; the evolving codebook (Level 1 and Level 2) can be accessed through this link: https://docs.google.com/document/d/1Wem2D7swkK0jRjZgnHyRiyebGOtYW9aDoTT8ks1nh0/edit?usp=sharing 
Table 1

Selected Level 1, Level 2, and Level 3 key themes grouped under five broad areas of mobile learning.

\begin{tabular}{|l|l|l|}
\hline - Level 1 & O Level 2 & $\mathbf{D}$ Level 3 \\
\hline
\end{tabular}

(1) Philosophical and theoretical frameworks

- $\quad$ Learning theories relevant to new practice

o Constructivist learning

o Situated learning

- $\quad$ Socio-cultural activity theory

\section{- Context-aware learning}

o Context (relevance of the environment and the learning issue)

- Socialising (interpersonal relationships)

o Communication (social setting / degree of communication between learners)

- Socio-cultural ecological approach

o Life-worlds (socio-cultural background of users)

o Participatory culture

- Significance of mobile devices in the life-worlds of users

- Opportunities to participate and to develop necessary cultural competencies and social skills

o Media landscape (range of media instances and affordances available)

o Cultural resources - Integrative view of mobile devices within the context of media convergence and integration

o Learner-generated content and contexts

o Appropriation

- $\quad$ Complexity in mobile learning

o Systems thinking principles in mobile learning

o Self-organisation of learning systems

- $\quad$ Unspecified frameworks

(2) Mobile learning research (theory and findings)

- $\quad$ Research methods in mobile learning

o Design-based research

o Action research

o Experimental studies

- Studies that are suitable for evaluating new design ideas and/or

o Basic research theories

- $\quad$ Research purposes

o Understanding

o Evaluating

- $\quad$ Findings from previous mobile learning research and reports

- Distribution of research outcomes across sectors

- Distribution of educational contexts by mobile device

- Categories of research directions in mobile learning

\section{(3) Pedagogies and learning methodologies}

- $\quad$ Phases of mobile learning history

o I. Focus on devices

o II. Focus on learning outside the classroom

o III. Focus on mobility of the learner (cross-contexts)

- Mobile learning pedagogies
o Contextual use of mobile learning
o PAH continuum (pedagogy - andragogy - heutagogy)
o Learners conceptions around mobile learning

- Indigenous learners and pedagogy

o Access and equity to education opportunities

o Barriers and enablers 


\section{o Cultural and universal values}

- $\quad$ Guidelines to inform educational practices and policy

- Connected social learning

- Heutagogy

- $\quad$ BYOD - bring your own device

(4) Mobile learning affordances

- $\quad$ Mobile learning affordances

o Augmented Reality (AR)

- $\quad$ AR and digital augmentation as particularly important in usergenerated contexts and meaning-making

o Virtual reality (VR)

o Mixed realities (MR)

- The MR continuum

o Real reality/real environment (RR)

o Mobility

- Offline / analogue components of MR

o Digital/online spaces

- Mobility as being disruptive to learners

o Social media

- Ethical considerations of online and/or public spaces

- Academic social media

- Social learning and distributed learning

- Online communities of practice/connected collaboration and practice

- Multimedia production

- Geo-location and proximity triggers

- 360 degree panoramic photos and videos

\section{(5) Key issues in mobile learning}

- Key issues in mobile learning

o Development for education professionals

- Lack of research on how teachers can engage with heutagogy through learning technologies

o Public, personal and intimate spaces and ethical considerations

- Risks of device to machine communication without owner/learner consent

- Transmission of location data

- Lack of privacy and intimacy in digital spaces

o Learner-generated content and contexts

- Mobile learning and individual/collective meaning-making occurring as situated in contexts and situations

- Static and dynamic (evolving) dimensions of learning contexts

o Affective, aesthetics and emotional factors in mobile learning

\section{BYOD}

Interface between formal, informal and non-formal contexts and settings

- Challenges and opportunities offered by mobile devices to learn outside formalised institutions and across contexts

o Mobile learning and effective/culturally-responsive design principles

o Research and development in mobile learning innovation and implementation

Building relationships and trust in mobile learning spaces

Face-to-face and offline components of mobile learning

Teacher/practitioner support

Institutional uptake, transformation, and change

Change rate of emerging and innovative learning technologies

- Strategies to account and absorb the constant innovation of mobile technologies

The above set of selected key themes identified from the literature provide a panorama of some of the important factors and considerations determining a reconceptualisation of mobile learning. This complex 
and dynamically evolving selected ecology of mobile learning themes are here to be (re)considered around the learner-generated learning potential of newer emerging digital affordances, such as mobile AR and VR. We see that these two current mobile learning affordances, complemented though relevant approaches to research and practice in complex mobile learning settings, while promoting authentic, connected and distributed social learning, are critical to reconceptualise learning through mobile devices. In the next section, we explore this further.

\section{Prospects for learner-generated learning through mobile AR and VR}

The literature review has shown that mobile learning as a research field has matured since the first attempts at large scale exploratory projects in the early 2000's. Indeed, mobile devices (particularly the smartphone) have become deeply embedded in the daily lives of the twenty-first century society, with an adoption rate nearing $100 \%$ worldwide (International Telecommunications Union, 2016). However, mobile learning has failed to realise the potential of revolutionising education (Traxler, 2016). We continue to substitute and augment prior pedagogical practices via new technology and publish the analysis of these case studies (Rushby, 2012). In order to transform educational practice, we need to ground mobile learning research in methodologies that are explicitly informed by new learning theories and pedagogical practices that move from knowing to being, and from developing student competence to capability: creativity, problem solving, collaboration, and resilience (Hase \& Kenyon, 2007). This in recognition of the complex, unpredictable, and ever-evolving social, cultural, ecological, educational, technological, and other settings and conditions of connected social mobile learning, which calls for insights from complexity theory in education (Aguayo et al., 2016; Meadows, 2008; Somekh, 2007).

Complexity theory in education, which refers to the employment of complexity science in education as an epistemological lens, looks at educational settings as complex, dynamic (ever-evolving), and unpredictable educational systems (Davis \& Sumara, 2005; Morrison, 2002). Within such systems, the role of mobile technology as a mediating tool is to actively facilitate the learning process in learners in culturally responsive and meaningful ways (Aguayo, 2014; Aguayo \& Eames, 2017). This process not only can be designed to occur as learner-generated learning through emerging learning affordances, such as mobile augmented reality and mobile virtual reality, but also by enhancing authentic and socially relevant modes of learning (Aguayo, 2016; Hase \& Kenyon, 2007). Furthermore, within such epistemology, both learners and mobile technologies can be seen as learning actors, where the shared interaction between them (through the technological affordances of mobile devices) can produce the learning process to emerge out of such interaction (Aguayo, Veloz \& Razeto-Barry, 2017; Jorg, 2000; Sumara \& Davis, 1997).

In this sense, we must leverage the unique affordances of mobile devices that support authentic learnergenerated content and learner-generated contexts within complex and ever-evolving educational settings (Luckin et al., 2010). Design based research, which has the ability to bridge the theory and practice gap and is capable of creating transferrable knowledge within ever-evolving tools and environments, provides such a foundation (Cook \& Santos, 2016; van de Akker, Bannan, Kelly, Nieveen, \& Plomp, 2010). We further argue that mobile augmented reality (AR), mobile virtual reality (VR), and mixed reality (MR) environments, that is the existing analogue to digital continuum encompassing AR and VR within real life settings (FitzGerald et al., 2013), are current key mobile affordances that can support the design of learner-determined environments. In the following section, we explore these in relation to the five broad areas and themes identified by the literature review.

Theoretical frameworks

While the literature review has revealed the breadth of theoretical frameworks employed in mobile learning, theoretical frameworks that are particularly relevant for informing the design of learnergenerated mobile AR and VR content and contexts include: social constructivism, connectivism, authentic learning, rhizomatic learning, and problem based learning (Bannan, Cook, \& Pachler, 2015; Cook \& Santos, 2016). Other theoretical frameworks that can provide with useful insights in the design of authentic learning environments within complex and unpredictable settings are socio-cultural activity theory and complexity theory applied in education (Aguayo, 2016; Frohberg et al. (2009); Hase \& Kenyon, 2007; Morrison, 2002). 
Due to the recent, and rapidly changing and emerging nature of the technology that surrounds mobile AR and VR affordances, there is relatively limited published research in learner-generated mobile AR and VR (Cochrane, 2016; Cochrane, Narayan, \& Antonczak, 2016; FitzGerald et al., 2013; Hussein \& Natterdal, 2015). This will change rapidly with the development of special interest research groups, such as the Ascilite mobile learning special interest group (http://ascilite.org/get-involved/sigs/mobilelearning-sig/), the immersive Learning Research Network (https://immersivelrn.org/about-us/what-is$\underline{\mathrm{ilrn} / \text { ), }}$, and other similar research clusters around the globe targeting these emerging mobile affordances.

Mobile learning pedagogy and practice

What literature that exists is largely centred upon mobile AR and VR as delivery platforms for teacher developed material and scenarios (Butchart, 2011; Coimbra, Cardoso, \& Mateus, 2015; Delello, McWhorter, \& Camp, 2015; FitzGerald et al., 2013). We believe that heutagogy (Blaschke \& Hase, 2015; Hase \& Kenyon, 2007) encapsulates a theoretical perspective to guide mobile learning pedagogy and practice towards empowering learner-generated AR and VR content and contexts. In the short term we also see the contextual use of mobile learning, most of the time through BYOD approaches, and connecting within social media spaces, as having a major influence on the impact of learner-generated AR and VR (Cook \& Santos, 2016; Pachler et al., 2010) related pedagogies and practice.

\section{Mobile learning affordances}

Augmented reality has been a key affordance of mobile learning since the emergence of mobile AR browsers that enable creation and sharing of user-generated content (Butchart, 2011). These include: Wikitude, Aurasma, Layar, and (formerly) Junaio. Mobile AR suffered a misstep through Google's defunct Google Glass project that failed to consider the social impact of always on AR glasses (Gross, 2014). The social acceptance of wearable mobile technologies is still emergent (Alvarez, Bower, Freitas, Gregory \& Wit, 2016) and mainstream social acceptance is apparently currently limited to smartwatches and personal fitness trackers. Mobile VR is a more recent mobile learning affordance enabled by the development of high screen resolution and 64 bit processor based smartphones alongside the availability of low cost head-mounted devices (HMD), such as Google Cardboard and compatible headsets (Amer \& Peralez, 2014). Learner-generated mobile VR has become enabled through the recent release of low cost 360 degree cameras designed to accompany smartphone-based 360 image and video stitching and sharing applications. The sharing of mobile VR content is also directly linked to the embedding of user-generated content within social networks such as Facebook, Wordpress, Twitter, and Google Streetview, among others. Thus, we see the emergence of an ecology of resources based upon mobile social networks to support learner-generated AR and VR content (Cochrane, 2016; Cochrane, Cook, Aiello, Harrison, \& Aguayo, 2016).

Key issues in mobile learning

Key issues surrounding mobile AR and VR in education include the ethical and health implications of these technologies (Andrews, Dyson, \& Wishart, 2013; Dyson, Andrews, Smith, \& Wallace, 2013; Lally, Sharples, Tracy, Bertram, \& Masters, 2012). A recurrent issue in mobile learning research is also the need to move beyond case studies and uncritical positivist approaches to a more critical and transferable methodology such as design-based research (DBR) that embeds iterative project design and evaluation leading to the creation of refined design principles transferrable to other academic contexts (Bannan et al., 2015; Cook \& Santos, 2016; Reeves, 2006).

\section{Moving forward}

We argue that the recent focus upon design-based research to inform the identification of transferable design principles for implementing learner-generated content and contexts via authentic mobile learning, in combination with considerations from complexity theory in education, provides the way forward for mobile learning to become a real catalyst for transforming pedagogy across complex settings (Aguayo, 2016; Cochrane \& Narayan, 2016, 2017; Cochrane, Narayan, \& Oldfield, 2015; Narayan \& Herrington, 2014). A key design principle is enabling authentic learning experiences (Herrington, Reeves, \& Oliver, 2010) through the use of augmented and virtual reality (Aguayo, Cochrane, \& Narayan, 2016a, 2016b; Cochrane et al., 2016). The focus of research and mobile learning hence moves beyond the tools and their affordances to operationalising and utilising the unique affordances of mobile learning - mobility and ability to create contexts (Cook \& Santos, 2016) by embedding and exploiting innovative and transformative pedagogies to empower and engage the learner in the learning process. 
Mobile learning is still evolving and unfolding at a rapid rate on a global scale. Unlike other learning innovations, such as elearning, mobile learning is informed by practices and innovations outside of formal institutional boundary (Traxler, 2016). As a result, new mobile affordances and capabilities such as AR and VR spring to life unexpectedly, yet are to become the norm and eventually old affordances. Therefore, we argue the need to move away from a focus on mobile apps as content-delivery platforms for learning, to situating the apps and their affordances within effective and open pedagogies, such as heutagogy, authentic learning, and Pedagogy 2.0 (McLoughlin \& Lee, 2008). We also argue for research approaches (such as design-based research, and complexity theory in education) that are agile, future focused and future-proof, and adaptable to complex settings, which allows for creativity and innovation in learning and teaching practices and the creation of transferrable knowledge to emerge. In this sense, we see that mobile learning and its plethora of growing theories, pedagogies, research and practice ought to focus on innovative pedagogies as a process, rather than a rigid structure and content-delivery platform. We believe that within such view old, current, and emerging affordances yet to come can be implemented to in turn facilitate open pedagogies in transformative ways.

\section{Summary}

The literature highlights that mobile learning research and practice has progressed through three identifiable stages: the mobility of the device, learning beyond the classroom, and the mobility of the learner (Cook \& Santos, 2016; Pachler et al., 2010; Sharples, 2009). The growing ubiquity of mobile devices throughout society has led to a social-cultural acceptance into everyday life practices. However, the literature indicates there is still a relatively low uptake of mobile learning across all levels of education, and in particular within higher education, in particular mobile learning underpinned by heutagogy as a guiding framework to enable learner-generated content and learner-generated contexts. Mobile learning research and practice needs to move beyond a niche field to gain mainstream impact and transform pedagogy. The extent of this trend is demonstrated by the lack of inclusion of mobile learning research in open access peer reviewed journals within the top ten ranked educational technology journals by Google Scholar (2015). Mobile learning research articles are underrepresented in these journals. For example, percentages of total articles from 2011 to 2016 based upon a basic keyword search for: mlearning, mobile learning, or m-learning: International Review of Research in Open and Distributed Learning (6\%), Education Technology and Society (3\%), the Australasian Journal of Educational Technology (2\%), the Turkish Online Journal of Educational Technology (2\%), and IEEE Transactions on Learning Technologies (2\%). Another evident trend we can see in the reviewed literature is the lack of conceptual and theoretical frameworks unique to mobile learning.

We argue that the emergent domains of new mobile learning affordances, such as connected mobile social media, mobile augmented reality and mobile virtual reality, provide fertile ground for founding mobile learning research and practice firmly within the framework of designing authentic learning experiences that leverage learner-generated content and contexts (heutagogy) using mobile devices. Along with heutagogy and authentic learning, and the unpredictable nature of mobile development and educational settings, we need to consider pragmatic approaches to research and learning within complex environments. We believe an open, adaptable, and agile approach to learning and research will allow practitioners and researchers to embrace the rapid and complex change and advancements in tools and affordances, and within settings, to explore the unseen and undiscovered, and theorise new meanings and frameworks leading to better pedagogical practice and understanding of mobile learning. This is epitomised in the concept of the scholarship of technology enhanced learning or SOTEL (Haynes, 2016).

\section{Conclusions}

The literature review shows that the past decade and a half of mobile learning research has followed the typical hype cycle associated with new technology as educators attempt to integrate it into both research and practice. While some commentators call out the failure of mobile learning to revolutionise learning (Traxler, 2016), others see the confluence of social media, mobile devices, design-based research, augmented reality, and virtual reality as a new state-of-the-art that can finally move mobile learning towards enabling authentic learner-generated content and contexts (Cook \& Santos, 2016). Reflecting upon our review of the literature surrounding mobile learning, we make a plea for heeding Cook and Santos call for exploring design-based research, within complexity, to guide mobile learning research and 
practice informed by a rigorous scholarship of technology enhanced learning. This will ensure explorations of emerging technologies and affordances, such as mobile AR and VR, are grounded in appropriate pedagogical strategies and informed by learning theory.

\section{References}

Aguayo, C. (2016). Activity theory and community education for sustainability: When systems meet reality. In D. Gedera, \& J. Williams (Eds.), Activity theory in education: Research and practice (pp. 139-151). Rotterdam: Sense Publishers.

Aguayo, C., Cochrane, T., \& Narayan, V. (2016a, October). Mobile learning in sustainability education: What, when, why and how? Paper presented at the AAEE16: Tomorrow making - Our present to the future, Adelaide.

Aguayo, C., Cochrane, T., \& Narayan, V. (2016b, February). Mobile learning technologies for sustainability education. Paper presented at the NZAEE16: Activate, Agitate, Advocate, Auckland.

Aguayo, C. \& Eames, C. (2017). Community partnerships in sustainability education research. In R. McNae, \& B. Cowie (Eds.), Realizing innovative partnerships in educational research (pp. 235-244). Rotterdam: Sense Publishers.

Aguayo, C., Higgins, B., Field, E., Nicholls, J., Pudin, S., Tiu, S. A., ... Mah, J. (2016). Perspectives from emerging researchers: What next in EE/SE research? Australian Journal of Environmental Education, 32(1), 17-29. https://doi.org/10.1017/aee.2015.57

Aguayo, C., Veloz, T., \& Razeto-Barry, P. (2017). Autopoietic principles and processes in the development of digital affordances in education. Manuscript submitted for publication.

Alvarez, V., Bower, M., Freitas, S. d., Gregory, S., \& Wit, B. d. (2016, October). The use of wearable technologies in Australian universities: Examples from environmental science, cognitive and brain sciences and teacher training. Paper presented at the Mobile Learning Futures - Sustaining Quality Research and Practice in Mobile Learning, Sydney.

Amer, A., \& Peralez, P. (2014, October). Affordable altered perspectives: Making augmented and virtual reality technology accessible. Paper presented at the Global Humanitarian Technology Conference, San Jose, CA, USA.

Andrews, T., Dyson, L., \& Wishart, J. (2013). Supporting practitioners in implementing mobile learning and overcoming ethical concerns: A scenario-based approach. QScience Proceedings, 2013(3), 10. https://doi.org/10.5339/qproc.2013.mlearn.10

Attewell, J., Savill-Smith, C. \& Douch, R. (2009). The impact of mobile learning: Examining what it means for teaching and learning. London: Learning and Skills Network.

Bannan, B., Cook, J., \& Pachler, N. (2015). Reconceptualizing design research in the age of mobile learning. Interactive Learning Environments, 24(5), 1-16. https://doi.org/10.1080/10494820.2015.1018911

Benbasat, I. (1985). An analysis of research methodologies. In F. MacFarlan (Ed.), The information system research challenge (pp. 47-85). Boston, MA: Harvard Business School Press.

Blaschke, L., \& Hase, S. (2015). Heutagogy, technology, and lifelong learning for professional and parttime learners. In A. Dailey-Hebert, \& K. S. Dennis (Eds.), Transformative perspectives and processes in higher education (Vol. 6, pp. 75-94). Switzerland: Springer International Publishing.

Bloom B.S. (1953) Thought processes in lectures and discussions. Journal of General Education, 7(ISS), 160-169.

Butchart, B. (2011). TechWatch report: Augmented reality for smartphones. Retrieved from http://observatory.jisc.ac.uk/docs/AR_Smartphones.pdf

Cochrane, T. (2014). Critical success factors for transforming pedagogy with mobile Web 2.0. British Journal of Educational Technology, 45(1), 65-82. https://doi.org/10.1111/j.1467-8535.2012.01384.X

Cochrane, T. (2016). Mobile VR in education: From the fringe to the mainstream. International Journal of Mobile and Blended Learning, 8(4), 45-61. https://doi.org/10.4018/IJMBL.2016100104

Cochrane, T., Cook, S., Aiello, S., Harrison, D., \& Aguayo, C. (2016, November). Designing virtual reality environments for paramedic education: MESH360. Paper presented at ASCILITE 2016: Show Me The Learning, Adelaide.

Cochrane, T., \& Narayan, V. (2016). Principles of modeling COPs for pedagogical change: Lessons learnt from practice 2006 to 2014. In J. McDonald, \& A. Cater-Steel (Eds.), Implementing communities of practice in higher education: Dreamers and schemers (Vol. IV, pp. 619-643). Singapore: Springer.

Cochrane, T., \& Narayan, V. (2017). Design considerations for mobile learning. In C. Reigeluth, B. J. 
Beatty, \& R. Myers (Eds.), Instructional-design theories and models (Vol. 4, pp. 385-414). New York, NY: Routledge.

Cochrane, T., Narayan, V., \& Antonczak, L. (2016). A framework for designing collaborative learning environments using mobile AR. Journal of Interactive Learning Research, 27(4), 293-316.

Cochrane, T., Narayan, V., \& Oldfield, J. (2015). Emerging technologies in New Zealand: A pedagogical framework for mobile social media. In V. Bozalek, D. Ngambi, A. Amory, J. Hardman, D. Wood, \& J. Herrington (Eds.), Activity theory, authentic learning, and emerging technologies: Southern perspectives (pp. 126-143). New York, NY: Routledge.

Coimbra, M. T., Cardoso, T., \& Mateus, A. (2015). Augmented reality: An enhancer for higher education students in math's learning? Procedia Computer Science, 67(2015), 332-339. http://doi.org/10.1016/j.procs.2015.09.277

Cook, J., \& Santos, P. (2016). Three phases of mobile learning state of the art and case of mobile help seeking tool for the health care sector. In D. Churchill, J. Lu, T. K. F. Chiu, \& B. Fox (Eds.), Mobile learning design (pp. 315-333). Singapore: Springer.

Davis, B., \& Sumara, D. (2005). Complexity science and educational action research: Toward a pragmatics of transformation. Educational Action Research, 13(3), 453-464.

Delello, J. A., McWhorter, R. R., \& Camp, K. M. (2015). Integrating augmented reality in higher education: A multidisciplinary study of student perceptions. Journal of Educational Multimedia and Hypermedia, 24(3), 209-233.

Dohn, N. B. (2009). Affordances revisited: Articulating a Merleau-Pontian view. International Journal of Computer-Supported Collaborative Learning, 4(2), 151-170.

Dourish, P. (2004) What we talk about when we talk about context, personal and ubiquitous computing. Personal and Ubiquitous Computing, 8(1), 19-30.

Dyson, L., Andrews, T., Smith, R., \& Wallace, R. (2013). Toward a holistic framework for ethical mobile learning. In Z. Berge, \& L. Muilenburg (Eds.), Handbook of Mobile Learning (pp. 405-416). New York, NY: Routledge.

Engeström, Y. (1987) Learning by expanding: An activity-theoretical approach to developmental research. Helsinki: Orienta-Konsultit.

FitzGerald, E., Ferguson, R., Adams, A., Gaved, M., Mor, Y., \& Thomas, R. (2013). Augmented reality and mobile learning: The state of the art. International Journal of Mobile and Blended Learning, 5(4), 43-58. https://doi.org/10.4018/ijmbl.2013100103

Frielick, S. \& Sciascia, A. D. (Eds.) (2016). \#npf14lmd: Learners and mobile devices: National project fund report. Wellington. Retrieved from http://mobilelearners.nz

Frohberg, D., Göth, C., \& Schwabe, G. (2009). Mobile learning projects - a critical analysis of the state of the art. Journal of Computer Assisted Learning, 25(4), 307-331. https://doi.org/10.1111/j.13652729.2009.00315.x

Google Scholar (2015). Top publications - educational technology. Retrieved from https://scholar.google.co.nz/citations?view_op=top_venues\&hl=en\&vq=soc_educationaltechnology

Gross, A. (2014). What's the problem with Google Glass? Retrieved from http://www.newyorker.com/business/currency/whats-the-problem-with-google-glass

Hase, S., \& Kenyon, C. (2007). Heutagogy: A child of complexity theory. Complicity: An International Journal of Complexity and Education, 4(1), 111-118.

Hase, S., \& Kenyon, C. (2013). Self-determined learning: Heutagogy in action. London: Bloomsbury Academic.

Haynes, D. (2016). Introducing SOTEL. International Journal for the Scholarship of Technology Enhanced Learning, 1(1), 1-2.

Herrington, J., Reeves, T. C., \& Oliver, R. (2010). A guide to authentic e-learning. New York, NY: Routledge.

Hung, J. L., \& Zhang, K. (2012). Examining mobile learning trends 2003-2008: A categorical meta-trend analysis using text mining techniques. Journal of Computing in Higher education, 24(1), 1-17.

Hussein, M., \& Natterdal, C. (2015). The benefits of virtual reality in education: A comparison study. (Bachelor thesis). Chlamers University of Technology, University of Gothenburg, Göteborg, Sweden. Retrieved from http://hdl.handle.net/2077/39977

Hwang, G. J., \& Tsai, C. C. (2011). Research trend in mobile and ubiquitous learning: A review of publications in selected journal from 2001 to 2010. British Journal of Education Technology, 42(4), E65-E70.

International Telecommunication Union. (2016). ICT facts and figures 2016. Retrieved from https://www.itu.int/en/ITU-D/Statistics/Documents/facts/ICTFactsFigures2016.pdf 
Jorg, T. (2000). About the unexpected: Complexity of learning based on reciprocity and human agency. Chaos and Complexity Theory Special Interest Group Newsletter. Retrieved from http://www.udel.edu/aeracc/library/Fall00.htm

Klopfer, E., Squire, K., \& Jenkins, H. (2002). Environmental detectives: PDAs as a window into a virtual simulated world. Proceedings of Wireless and Mobile Technologies in Education, IEEE International Workshop, Växjö, Sweden, 95-98.

Knight, E., Gunawardena, C., \& Aydin, C. H. (2009). Cultural interpretations of the visual meaning of icons and images used in North American web design. Educational Media International, 46(1), 17-35.

Kress, G., \& Pachler, N. (2007). Thinking about the ' $\mathrm{m}$ ' in m-learning. In N. Pachler (Ed.) Mobile learning: Towards a research agenda (pp. 7-32). London: Institute of Education. Retrieved from http://www.wlecentre.ac.uk/cms/files/occasionalpapers/mobilelearning_pachler_2007.pdf.WLE Centre Occasional Papers 1

Kukulska-Hulme, A., Sharples, M., Milrad, M., Arnedillo-Sanchez, I. \& Vavoula, G. (2009). Innovation in mobile learning: A European perspective. International Journal of Mobile and Blended Learning, 1(1), 13-35.

Lally, V., Sharples, M., Tracy, F., Bertram, N., \& Masters, S. (2012). Researching the ethical dimensions of mobile, ubiquitous and immersive technology enhanced learning (MUITEL): A thematic review and dialogue. Interactive Learning Environments, 20(3), 217-238. Retrieved from http://eprints.gla.ac.uk/46148/

La Pelle, N. (2004). Simplifying qualitative data analysis using general purpose software tools. Field Methods, 16(1), 85-108.

Lindsay, L. (2015). Transformation of teacher practice using mobile technology with one-to-one classes: M-learning pedagogical approaches. British Journal of Educational Technology, 47(5), 883-892. https://doi.org/ 10.1111/bjet.12265

Luckin, R., Clark, W., Garnett, F., Whitworth, A., Akass, J., Cook, J., ... Robertson, J. (2010). Learnergenerated contexts: A framework to support the effective use of technology for learning. In M. Lee, \& C. McLoughlin (Eds.), Web 2.0-based e-learning: Applying social informatics for tertiary teaching (pp. 70-84). Hershey, PA: IGI Global.

McGrenere, J., \& Ho, W. (2000, May). Affordances: Clarifying and evolving a concept. Paper presented at the Graphics Interface 2000, Montreal.

McLoughlin, C., \& Lee, M. J. W. (2008). The three P's of pedagogy for the networked society: Personalisation, participation and productivity. International Journal of Teaching and Learning in Higher Education, 20(1), 10-17. Retrieved from http://www.isetl.org/ijtlhe/pdf/IJTLHE395.pdf

Meadows, D. (2008). Thinking in systems: A primer. White River Junction, VT: Chelsea Green.

Merchant, G. (2012). Mobile practices in everyday life: Popular digital technologies and schooling revisited. British Journal of Educational Technology, 43(5), 770-782. https://doi.org/10.1111/j.14678535.2012.01352.x

Miles, M. B., \& Huberman, A. M. (1994). Qualitative data analysis: An expanded sourcebook. Thousand Oaks, CA: SAGE Publications.

Morrison, K. (2002). School leadership and complexity theory. London: RoutledgeFalmer.

Naismith, L., Lonsdale, P., Vavoula, G., \& Sharples, M. (2004). Literature review in mobile technologies and learning. In NESTA Futurelab Literature review series (Report 11). Retrieved from https://telearn.archives-ouvertes.fr/hal-00190143/document

Narayan, V., \& Herrington, J. (2014, November). Towards a theoretical mobile heutagogy framework. Paper presented at ASCILITE 2014: The Rhetoric and Reality: Critical perspectives on educational technology, Dunedin.

O’Malley, C., Vavoula, G., Glew, J., Taylor, J., Sharples, M., \& Lefrere, P. (2003). Guidelines for learning/teaching/tutoring in a mobile environment. Mobilearn project deliverable. Retrieved from http://kn.open.ac.uk/public/document.cfm?docid=7232.

Pachler, N., Bachmair, B., \& Cook, J. (2010). Mobile learning: Structures, agency, practices. Boston, MA: Springer. Retrieved from http://link.springer.com/10.1007/978-1-4419-0585-7

Parsons, D. (Ed.). (2012). Innovations in mobile educational technologies and applications. Hershey, PA: IGI Global.

Parsons, D. (2014). A mobile learning overview by timeline and mind map. International Journal of Mobile and Blended Learning, 6(4), 1-21. https://doi.org/10.4018/ijmbl.2014100101

Reeves, T. C. (2006). Design research from a technology perspective. In J. van den Akker, K. Gravemeijer, S. McKenney, \& N. Nieveen (Eds.), Educational design research (pp. 52-66). New York, NY: Routledge. 
Rushby, N. (2012). Editorial: An agenda for mobile learning. British Journal of Educational Technology, 43(3), 355-356. https://doi.org/10.1111/j.1467-8535.2012.01313.x

Sharples, M. (2006). Big issues in mobile learning. In Report of a workshop by the Kaleidoscope Network of Excellence Mobile Learning Initiative (pp. 1-37). Nottingham: Learning Sciences Research Institute.

Sharples M., Taylor J. \& Vavoula G. (2007) A theory of learning for the mobile age. In R. Andrews, \& C. Haythornthwaite (Eds.), The Sage Handbook of Elearning Research, (pp. 221-247). Sage, London.

Somekh, B. (2007). Pedagogy and learning with ICT: Researching the art of innovation. New York, NY: Routledge.

Sumara, D., \& Davis, B. (1997). Enactivist theory and community learning: Toward a complexified understanding of action research. Educational Action Research, 5(3), 403-422.

Taylor J., Sharples M., Malley C.O’,Vavoula G. \& Waycott J. (2006) Towards a task model for mobile learning: a dialectical approach. International Journal of Learning Technology, 2(2-3), 138-158.

Traxler, J. (2010). Will student devices deliver innovation, inclusion, and transformation? Journal of the Research Center for Educational Technology, 6(1), 3-15.

Traxler, J. (2016). What killed the mobile learning dream? Retrieved from https://www.jisc.ac.uk/informfeature/what-killed-the-mobile-learning-dream-26-feb-2016?

van den Akker, J., Bannan, G., Kelly, A. E., Nieveen, N., \& Plomp, T. (2010). An introduction to educational design research. Netzodruk, Enschede: SLO Publications.

Wingkvist, A., \& Ericsson, M. (2011). A survey of research methods and purposes in mobile learning. International Journal of Mobile and Blended Learning, 3(1), 1-17. https://doi.org/10.4018/jmbl.2011010101

Wu, W.-H., Jim Wu, Y.-C., Chen, C.-Y., Kao, H.-Y., Lin, C.-H., \& Huang, S.-H. (2012). Review of trends from mobile learning studies: A meta-analysis. Computers \& Education, 59(2), 817-827. https://doi.org/10.1016/j.compedu.2012.03.016

Corresponding author: Claudio Aguayo, caguayo@aut.ac.nz

Australasian Journal of Educational Technology (c) 2017.

Please cite as: Aguayo, C., Cochrane, T., \& Narayan, V. (2017). Key themes in mobile learning: Prospects for learner-generated learning through AR and VR. Australasian Journal of Educational Technology, 33(6), 27-40. https://doi.org/10.14742/ajet.3671 